\title{
O mundo dos Marcondes de Sá: educação e instrução em duas gerações de uma família da elite campeira no Paraná oitocentista
}

\author{
The World of Marcondes de Sá: \\ Education and Instruction in Two Generations of a \\ Countryside Elite Family in the 19th Century's Paraná
}

Juarez José Tuchinski dos Anjos *,

Etienne Baldez Louzada Barbosa ${ }^{* *, 2}$

\section{Resumo}

$\mathrm{O}$ artigo interroga o relato memorialístico e a correspondência da família Marcondes de Oliveira e Sá com o intuito de investigar as práticas educativas. Essa família pertencia à chamada elite campeira paranaense. Acompanha o patriarca, barão de Tibagy, e seu filho, Jesuíno Marcondes de Oliveira e Sá, com o objetivo de identificar as práticas mobilizadas para a educação e instrução de alguns de seus filhos, bem como o lugar que elas ocupavam em suas vidas. A hipótese é de que a família se valia de um universo de práticas educativas comuns a esse grupo e a outros segmentos da população, porém, apropriando-as com base nas representações que tinha de seu lugar social e sua classe, com vistas à manutenção de um lugar de poder do qual a própria

\section{Abstract}

This article interrogates the memorialistic report and the correspondence of the Marcondes de Oliveira e Sá family, in order to investigate their educational practices. That family belonged to the so-called countryside elite of Paraná, and its patriarch was the farmer José Caetano de Oliveira, Baron of Tibagy. We will accompany the Baron and his son, Jesuíno Marcondes de Oliveira e Sá, aiming to identify the practices they mobilized for the education and instruction of some of their children, as well as the place education occupied in their lives. Our hypothesis is that this family used a universe of educational practices common to their group and other segments of the population, but appropriating them on the basis of representations of their social place and

\footnotetext{
* Universidade de Brasília (UnB), Faculdade de Educação, Departamento de Teorias e Fundamentos, Brasília, DF, Brasil. juarezdosanjos@yahoo.com.br <https://orcid.org/0000-0003-4677-5816>

** Professora Adjunta da Faculdade de Educação da Universidade de Brasília (UnB), Faculdade de Educação, Brasília, DF, Brasil. blb_etienne@hotmail.com <https://orcid.org/0000-0001-6780-3148>
} 
educação e a instrução eram elementos constituidores. A pesquisa vislumbrou um pouco desse mundo, percebendo a existência de dimensões (familiar, material, política e social) que se complementam e se fortalecem ao longo de duas gerações.

Palavras-chave: Paraná; século XIX; práticas educativas familiares; instrução. class, aiming to maintain a place of power, of which education and instruction were constituent elements. The research glimpsed a little of the family's world, realizing the existence of dimensions (familiar, material, political and social) that complement and strengthen each other over two generations.

Keywords: Paraná; 19th century; family educational practices; instruction.

Em 22 de março de 1857, José Caetano de Oliveira (dali a alguns meses, barão de Tibagy), fazendeiro da Província do Paraná enriquecido com o comércio de tropas, escrevia de Palmeira ao filho, Jesuíno Marcondes, então um político em ascensão no Império. Em meio a orientações e encaminhamentos de negócios, abriu espaço para abordar um assunto em particular: o nascimento do primeiro filho de Jesuíno:

Saudações à vossa mulher a quem dirás que tive o prazer em saber que o incômodo dela era gravidez, pois a Da Luz se acha pela mesma forma e, portanto, presumo que me devem estar satisfeitos, porque continuará minha família em aumento, que andava desconfiado que logo desapareceria esta descendência cá do mundo e à vista de agora deve atender-se que é preciso que seus progenitores empreguem os meios para adquirirem fortuna para os manterem com a decência que eu desejo. (Oliveira, 1857, p. 1)

A vinda de uma criança era, aos olhos do patriarca, um assunto importante, pois trazia consigo a responsabilidade de assegurar às novas gerações a mesma vida que ele, por meio do trabalho e das boas relações, conseguira proporcionar aos seus filhos. Do contato com a documentação que será interrogada neste trabalho, relativa aos Marcondes de Oliveira e Sá (sobrenome com o qual a família ficou mais conhecida), temos razões para crer que não era só a riqueza material o elemento de manutenção do lugar social familiar. Havia outro, que o barão procurou oferecer a Jesuíno desde a infância e este, por sua vez, ao filho que estava para nascer: ${ }^{3}$ a educação - entendida como a transmissão de hábitos, comportamentos e condutas - e a instrução - a aquisição dos saberes escolarizados -, desde o nível elementar até o superior. Nosso objetivo neste artigo é investigar as práticas que esses homens da família 
Marcondes mobilizavam para essa educação e instrução de alguns de seus filhos e o lugar que elas ocupavam em suas vidas.

Conforme define Roger Chartier (2002), as representações são “esquemas intelectuais incorporados que criam figuras graças às quais o presente pode adquirir sentido, o outro tornar-se inteligível e o espaço ser decifrado" (Chartier, 2002, p. 17). Com base nessas representações do mundo social - que são sempre coletivas, embora às vezes partilhadas somente por um grupo ou classe e não necessariamente por toda uma sociedade -, são realizadas, por meio das práticas individuais que as efetivam, diferentes apropriações, isto é, processos singulares pelos quais "é historicamente produzido um sentido e diferenciadamente construída uma significação" (Chartier, 2002, p. 24). Servindo-nos dos conceitos de representação e apropriação de Chartier, a hipótese da qual partimos é de que essa família, pertencente à chamada elite campeira paranaense, ${ }^{4}$ valia-se de um universo de práticas educativas comuns a esse grupo e a outros segmentos da população, porém, apropriando-as com base nas representações que tinha de seu lugar social e da classe ${ }^{5}$ à qual pertencia, com vistas à manutenção de um lugar de poder, do qual a própria educação e a instrução eram elementos constituidores.

Para identificar as representações e as práticas mobilizadas pelos Marcondes de Oliveira e Sá, optamos por interrogar, primordialmente, o relato memorialístico "Pai e Patrono". ${ }^{6}$ Escrito em 1927 por Moysés Marcondes de Oliveira e Sá (por ocasião da tomada de posse na Academia Paranaense de Letras, da cadeira que tinha seu pai, Jesuíno Marcondes, como patrono), esse escrito do ego narra, com base nas recordações pessoais do autor, passagens da vida de seu genitor e de seu avô, e, ancorado em vasta documentação familiar transcrita em meio às suas reminiscências - diários e correspondências -, algumas lembranças narradas pelo próprio pai a respeito do avô de Moysés, o barão de Tibagy, patriarca originador de toda a família.

Considerando que o estabelecimento de fontes solicita, dentre outros procedimentos, "transformar alguma coisa, que tinha sua posição e seu papel, em alguma outra coisa que funciona diferente" (Certeau, 2002, p. 83), optamos por "desmembrar" essa documentação, reorganizando-a, a fim de alçá-la ao status de testemunho histórico. Tal operação historiográfica tornou possível "escutarmos" na obra "Pai e Patrono" não apenas a voz de Moysés Marcondes acerca da educação que lhe dera seu pai (nos trechos de relato propriamente memorialístico), mas também da educação que este igualmente recebera desde a infância (nas cartas transcritas, nas quais Jesuíno confidencia aos destinatários lembranças de seu passado, assim como nas suas memórias familiares transmitidas a 
Moysés ao longo da vida) e da educação e instrução que Jesuíno queria para o próprio filho (em cartas dirigidas a este durante sua infância e juventude). Por fim, pode-se ouvir a voz do próprio barão de Tibagi, educando e instruindo Jesuíno, já que muitas das cartas que enviava ao filho foram transcritas na obra. No conjunto, essa polifonia abre para o historiador a possibilidade de reconstituir alguns vestígios do ciclo educativo de duas gerações dessa família, sempre de pai para filho: a educação/instrução dada/proporcionada pelo barão ao filho Jesuíno, entre 1827 e 1844, e a educação/instrução dada/proporcionada por Jesuíno ao filho Moysés, entre 1857 e 1881, aproximadamente.

Assim desmembrada a obra "Pai e Patrono", 7 deparamos com dois tipos de evidência a interrogar: o relato memorialístico e a correspondência familiar. No primeiro caso, consideramos que o texto de ego não é neutro, mas fruto de uma produção de memória que, como alertam Michael Pollak (1992) e Krzystof Pomian (2000), constrói uma imagem do passado baseada em vestígios concretos sobre as quais ele produz um significado. No segundo, tivemos presente que as correspondências, embora produzidas no "calor" dos acontecimentos relatados, são feitas tanto para ocultar como para revelar (Perrot, 2009), de modo que nos dão acesso não a uma realidade "nua e crua", mas antes, a uma realidade também interpretada, assumida, negada, ocultada, dada a ver pelo remetente ao destinatário. Em função disso, sempre procuramos ler os dois tipos de evidência de forma contrastada, a fim de que uma ajude a interpretar e compreender a outra.

Na primeira parte do artigo, adentraremos o "mundo dos Marcondes de Sá”. Em seguida, investigaremos a educação e a instrução transmitidas de pai para filho ao longo de duas gerações, encerrando com algumas considerações, à guisa de conclusão.

\section{O Mundo dos Marcondes de Sá}

Na região paranaense formada por florestas e planícies de vegetação rasteira que cobrem a porção de terra desde a cidade da Lapa até Guarapuava e que, por essas características topográficas, fora batizada de "Campos Gerais", localizava-se o que temos chamado em nossas pesquisas de o "mundo dos Marcondes de Sá”.

De forma resumida, a região dos Campos Gerais, no estado do Paraná, teve sua identidade histórica e cultural constituída ao longo do século XVIII, sendo descrita pela historiografia como um território com "ricos pastos naturais, abundância de invernadas com boa água e relevo suave” (Melo; Moro; Guimarães, 
2007, p. 18) e que proporcionaram o desenvolvimento de atividades de criação e de engorda de animais, bem como a prática do tropeirismo. Geograficamente, os Campos Gerais estavam em território propício para entreposto entre o sul e o sudeste do Paraná, bem como para a constituição de uma rota até os centros comerciais do Império. Dessa forma, era ponto de criação, parada, comércio, fixação de moradias e trânsito de tropeiros, enfim, uma importante localização econômica na província paranaense (Oliveira, 2014).

A fazenda - ou, como chamamos, o Mundo dos Marcondes - fazia parte desse importante território, no século XIX. Com essa expressão não classificamos somente o mundo físico, material, mas também queremos designar um conjunto de vivências e experiências históricas de um grupo de sujeitos, unidos por laços de sangue. Um mundo constituído por quatro dimensões intrínsecas: a dimensão material, a familiar, a política e a social.

$\mathrm{Na}$ sua dimensão material, esse mundo começou a ser construído pelos avós maternos de Jesuíno, o tenente Manoel José de Araújo e sua esposa, Anna Maria da Conceição, por volta de 1772. Naquele ano, casaram-se e doaram as terras necessárias para a transferência da freguesia de Tamanduá para o local denominado Palmeira, mesmo nome da fazenda da família. Com o falecimento de Manoel José em 1825, a Fazenda foi subdividida entre os herdeiros. À mãe de Jesuíno, Cherubina Rosa Marcondes de Sá - que já estava casada com o sorocabano José Caetano de Oliveira havia pouco mais de uma década -, coube o sítio denominado Rincão da Cria (Marcondes, 2009, p. 13-15). O patrimônio familiar dos Marcondes de Sá teve início não com uma aliança matrimonial, mas com o terreno legado a Cherubina pelo avô de Jesuíno, uma vez que José Caetano, "filho de boa gente e aparentado com as melhores famílias da terra, era, todavia, pobre" (Marcondes, 2009, p. 15). A propriedade inseria-se numa economia local em que predominava a criação e posteriormente a condução e invernagem das tropas muares. José Caetano, para ampliar o patrimônio herdado, criou ali o seu gado, mas também se dedicou ao "negócio mais rendoso da época, de compra e venda de tropas muares que, adquiridas no extremo Sul, vinham ser engordadas nos campos da zona paranaense" e eram vendidas nas feiras de Sorocaba, de onde seguiam para "São Paulo, Minas Gerais, Rio de Janeiro e Bahia”, conforme narra Moysés Marcondes (Marcondes, 2009, p. 17).

$\mathrm{Na}$ dimensão familiar do mundo dos Marcondes de Sá, por força de seu trabalho de tropeiro, José Caetano passava "em casa dois ou três meses do ano" (Oliveira e Sá, 1899, apud Marcondes, 2009, p. 93). Enquanto o patriarca cuidava dos negócios rentáveis, a matriarca cuidava da casa, da roça, das roupas, da prole e dos criados. ${ }^{8}$ Nesse ambiente rural, entre uma viagem e 
outra, é que foram tendo seus filhos, três homens e cinco mulheres, das quais uma faleceu na infância (Marcondes, 2009, p. 16). Foi em 1827 que nasceu Jesuíno, o quarto filho do casal e aquele para quem parece ter se voltado boa parte da atenção e afeição paternas. Podemos perceber alguns momentos dessa vida campeira dos Marcondes contrapondo-a com a vida de parentes próximos, que viviam no Rincão do Manhoso, também em Palmeira. O tio de Jesuíno por parte de mãe, Antonio Joaquim Camargo, era o proprietário do sítio referido. Segundo Zeloí dos Santos (2005), o cotidiano da família era marcado pelo cuidado com o gado e com tudo que do sítio poderia ser aproveitado (a lã dos carneiros que possibilitava a confecção de "baixeiros, coxonilhos, redes, cobertores, mantas, xales, etc.”; o leite das vacas que rendia queijos e manteigas, entre outros alimentos) e com a plantação feita pelos escravos para utilização na fazenda (milho, feijão, batata, mandioca e trigo) (Santos, 2005, p. 65). As atividades eram realizadas por todos, incluindo os filhos. Os momentos de lazer dos primos de Jesuíno talvez fossem muito semelhantes aos seus ou, em alguns momentos, talvez até fossem realizados conjuntamente, tomando em consideração o que relembrou anos depois "na freguesia, confabulávamos com a família dos tios Camargo e outros parentes” (Oliveira e Sá, 1899, apud Marcondes, 2009, p. 94) - ou o que demarcou Moysés Marcondes de Oliveira e Sá: "entre os elos que ligam as gerações de uma família, como as de uma nacionalidade, tem tamanha importância o das crenças familiares e tradicionais" (Marcondes, 2009, p. 19).

Enquanto essa vida transcorria na fazenda, a laboriosidade de José Caetano nos negócios não parava e, com ela, veio o aumento e consolidação do patrimônio familiar bem como sua afirmação política, no interior do Partido Liberal. Era essa a terceira dimensão do mundo dos Marcondes de Sá. No Partido, tornou-se membro respeitado, graças às relações que travou com Rafael Tobias de Aguiar durante a Revolução Liberal de 1842, tornando-se "íntimo amigo e correligionário [...] cuja política patrocinava nas Vilas de Serra Acima” (Marcondes, 2009, p.19). À medida que os filhos foram crescendo, a ampliação desse poder político foi sendo assegurada por meio de alianças matrimoniais, como a encetada pela sua filha Zeferina com o primo Antônio de Sá e Camargo, morador do sítio Rincão do Manhoso e futuro visconde de Guarapuava (Santos, 2005). Em 1855 foi a vez de Jesuíno dar sua contribuição à formação da segunda geração dos Marcondes e à consolidação do status quo familiar, casando-se com a morretense Domitila Alves de Araújo, filha de importante clã Liberal do litoral da recém-instalada Província do Paraná. Com isso, o alcance político da família tentaria fazer-se sentir - embora num reduto 
dominado pelo Partido Conservador - também nas Vilas de Serra Abaixo. Em 1858, o poder político e econômico dos Marcondes de Oliveira e Sá recebeu o reconhecimento imperial, pela outorga do título de barão do Tibagy ao Patriarca José Caetano de Oliveira, ao passo que a partir da década de 1860 foi a vez de Jesuíno atingir os altos escalões do Império, na condição de ministro imperial, e da Província, como vice-presidente (em várias ocasiões) e presidente, em 1889.

O mundo dos Marcondes de Sá possuía, ainda, uma dimensão social. Quando tomou posse da Fazenda, em 1825, José Caetano não se diferenciava muito dos habitantes dos Campos Gerais, com hábitos e costumes rústicos, preocupado apenas com o gado e o lucro imediato que podia auferir dessa atividade. Morava em uma casa simples, de madeira, que era motivo de gracejo de um seu cunhado, que ao visitá-lo pendurava o chapéu no beiral, tão baixo estava o telhado da casa (Marcondes, 2009, p. 16). Era um simples membro da sociedade campeira. Com o passar dos anos a residência modesta se converteu numa "vasta casa, tipo português e solarengo, à qual nem faltaram leões de louça sobre as colunas do portão de entrada" (Marcondes, 2009, p. 16), introduzindo ali "o luxo, raro na época, de vidros nas janelas, em substituição das usuais empanadas, e de mobília completa na sala” (Marcondes, 2009, p. 18). Como se vê, à medida que as outras dimensões do mundo dessa família se consolidavam, ela ia, também, aproximando-se mais e mais dos hábitos das famílias burguesas da Corte e da Europa, sem nunca abrir mão de estar integrada no ambiente bucólico e rural no qual estava inserida, mas fazendo desse seu contato com o mundo burguês o elemento que a diferenciava e demarcava seu status social nos Campos Gerais: ela tornava-se elite campeira. ${ }^{9}$ Por isso Moysés Marcondes de Oliveira e Sá (1859-1928), filho de Jesuíno com Domitila Alves de Araújo, já pôde nascer, diferentemente do pai e mesmo do avô, em uma casa grande, próspera, com pomar, animais para o consumo e pequenas plantações. Todavia, promover a manutenção desse mundo era tarefa partilhada por todos, tanto pais quanto filhos. E assim como Jesuíno, Moysés teve de participar igualmente disso.

Compreender a constituição do "mundo dos Marcondes" exige, portanto, entender também o lugar conferido à educação e à instrução na dinâmica familiar. Que práticas foram usadas para a educação e a instrução? Que apropriações eram feitas delas pelos homens dessa família? É o que tentaremos responder a seguir. 


\section{De PAI PARA FILHO: A EDUCAÇÃO NO MUNDO DOS MARCONDES DE SÁ}

Na documentação consultada pudemos identificar, ao menos, quatro práticas educativas e suas diferentes apropriações: o conselho paterno, o exemplo, a correção dos filhos como castigo moral e a leitura de livros em voz alta, nos serões familiares. Em função dos limites deste texto, exploraremos as duas primeiras: os conselhos paternos e o exemplo. ${ }^{10}$

Os conselhos paternos eram expressos tanto pessoalmente como, principalmente, por meio de cartas, já que durante boa parte da infância e juventude, as ambições familiares colocaram os filhos longe de casa, para receberem, em Pernambuco (Jesuíno) e São Paulo (Moysés), a instrução considerada por seus pais como ideal. Essa distância, entretanto, não impedia que certa educação fosse engendrada. É o que afirma no diário da sua primeira viagem à Europa, nos anos 1850, Jesuíno Marcondes de Oliveira e Sá: "Meus bons pais, a quem tanto devo, não poderiam abandonar toda a família e seus interesses, para irem dirigir a cem léguas de sua casa, a minha educação; mas seu zelo ardente se manifestava sobejo, em cartas cheias de salutares conselhos e nas recomendações que de mim faziam a seus amigos" (Oliveira e Sá apud Marcondes, 2009, p. 83).

Do mesmo artifício usado pelo barão de Tibagy valeu-se Jesuíno na educação dos seus filhos, conforme relata Moysés Marcondes em suas memórias: "De perto ou de longe encaminhava incansavelmente os seus, com direção, conselhos, estímulos e sacrifícios para o bom resultado da formação útil e prestativa, que para todos ambicionava. Suas cartas acompanhavam, passo a passo, a educação dos ausentes, sem nada descuidarem da conveniente orientação, em todos os sentidos" (Marcondes, 2009, p. 97).

Que orientações eram dadas nesses conselhos? No caso da relação barão-Jesuíno, no livro Pai e Patrono não foram transcritas as cartas relativas à sua infância. Entrementes, pode-se aventar, com base em evidências indiretas, que tenham tido conteúdo semelhante ao dos seus ditos, que a memória familiar conservou e Moysés Marcondes consignou por escrito. Se for plausível pensar assim, o barão provavelmente ensinava aos filhos, dentre outras atitudes, a constância necessária para atingir os objetivos na vida, pois "para crescer, é necessário começar por ser pequeno” (Marcondes, 2009, p. 16), rezava a resposta dada àquele cunhado que fazia troça da sua pobreza, nos primeiros anos. Por ter sido conservada na tradição oral da família, a frase deve ter sido repetida muitas vezes, indicando uma representação transmitida aos filhos, de que era preciso constância e perseverança para progredir, assim como ele, com esse 
comportamento, adquirira fortuna e poder, não obstante haver começado "pequeno" e pobre. O barão também pode ter ensinado algo similar ao que declarou, no seu leito de morte, acerca do que legava para os filhos: "Quis deixar um pão para cada um de meus filhos. Deixei-lhes o fermento" (Marcondes, 2009 , p. 17). Esse fermento parece ser, por um lado, os bens materiais, garantidores de futuro e da possibilidade de ampliação do patrimônio familiar por meio dos novos negócios (conselhos nesse sentido, aliás, eram dados frequentemente aos filhos, já adultos, por meio das cartas). Por outro lado, e principalmente, esse fermento pode dizer respeito à consciência de que certos hábitos e comportamentos que ele cultivara (como a laboriosidade) e transmitira por uma "boa" educação/instrução, assegurariam a manutenção do status alcançado e já consolidado ao final de sua vida.

Com mais segurança e amparados por evidências mais diretas, sabemos o que era objeto dos conselhos de Jesuíno a Moysés, já que constam na obra algumas das cartas enviadas por ele ao filho, dos 13 aos 18 anos, quando este era aluno no colégio anexo ao Seminário Episcopal de São Paulo. Analisemos dois desses conselhos paternos.

O trabalho comparece nos conselhos como elemento basilar para garantir a riqueza e a posição social. "Geralmente, os moços aspiram à riqueza, sem trabalho, às posições, sem merecimento, e não é raro ver-se a enfatuada loucura pretender alcançar tudo isso por meio do casamento" (Oliveira e Sá, 1877, apud Marcondes, 2009, p. 89), escreveu Jesuíno a Moysés em 1877. Como sabemos, a representação do trabalho como meio para alcançar riqueza fora uma constante na vida da primeira geração dos Marcondes de Sá, mas, à época em que escreve Jesuíno, já possuía diferentes significados, pois não mais dizia respeito à labuta braçal, mas antes, àquela de cunho intelectual, na qual ele penetrara e esperava que seu filho também penetrasse. Esquecendo-se de como um casamento fizera a diferença na vida de seu pai e de sua família (ainda que somado à sua laboriosidade), ao criticar situações semelhantes, aconselhava o filho a não buscar seu sucesso nesses subterfúgios, mas no próprio trabalho. Mas ensinava-o a valorizar o casamento pela dimensão religiosa a ele inerente e pelos compromissos múltiplos dali nascidos: "O casamento é a união mística de dois corações, que marcham juntos para a felicidade eterna, lutando neste triste mundo, para desempenharem seus deveres para com Deus, com a família e a sociedade" (Oliveira e Sá, 1877, apud Marcondes, 2009, p. 89). Se o casamento não deveria substituir o amor pelo trabalho, deveria ser manifestação do amor a Deus e às duas coletividades nas quais os noivos estariam inseridos: a família e a sociedade. Com isso, o pai ensinava ao filho que o casamento, mais 
do que um ato individual, devia ser encarado como um ato social e até mesmo místico. No primeiro caso, um ato de responsabilidade diante do clã familiar, para o qual se trariam novos elementos, tudo isso diante dos olhos da sociedade campeira de que formavam, então, uma elite. No segundo caso, era um dever para com Deus, presença sobrenatural sempre manifesta na religiosidade dos Marcondes de Sá, como se observa noutros conselhos, aqui, porém, inexplorados em função dos limites deste artigo.

Uma segunda prática educativa comum no solar e no mundo dos Marcondes de Oliveira e Sá era a do exemplo. Exemplo entendido em duplo sentido: a exemplaridade de situações ou pessoas cuja conduta deveria ser imitada ou não e o exemplo dado pelo pai aos filhos, como comportamento a ser copiado e adotado para si.

No primeiro caso, o da exemplaridade, ao voltar para casa de suas andanças pela Província, "trazia ele, para a família, alguma história edificante, a que a sua compassividade sabia dar relevo", recorda Moysés Marcondes a respeito do pai, Jesuíno. "Havia, para ele, nas virtudes dos humildes, um fulgor que nunca poderiam ter as dos mais felizes, como havia, nos erros e culpas dos ignorantes, motivos antes para compassiva correção do que para severidade despiedosa [sic]" (Marcondes, 2009, p. 78). É interessante o significado da exemplaridade proposta por Jesuíno. Os humildes, na sua simplicidade, possuiriam virtudes que os mais felizes (referindo-se, provavelmente, aos ricos ou a si próprio e os seus) jamais teriam. Talvez até mencionasse tais virtudes à família no intuito de que fossem incorporadas pelos filhos. Porém, ao afirmar que entre esses humildes também havia os ignorantes, possuidores de erros que não deviam ser encarados com falta de piedade, mas antes com compassividade, demarcava, implicitamente, a diferença que havia entre os Marcondes e aqueles, já que era aos primeiros que cabia ter a compaixão pelos segundos, numa atitude em princípio cristã, mas que, na verdade, estabelecia um lugar de poder em relação a esses "ignorantes", que estariam um degrau abaixo dos Marcondes de Sá na escala moral ou social. Com isso, Jesuíno ensinava e naturalizava, também aos filhos, as fraturas sociais existentes entre eles e os campeiros com os quais conviviam, lembrando que o lugar "mais alto" deveria ser ocupado por sua família.

No segundo caso, o do exemplo dado, Jesuíno ensinava também que, apesar das diferenças existentes entre os Marcondes e os membros mais humildes da sociedade (fosse a campeira ou a paranaense de modo geral), havia momentos nos quais aqueles deveriam ser tratados com igualdade e camaradagem. 
Quando criança, Moysés, regressando a cavalo com o pai em viagem pela estrada da Graciosa, abrigou-se numa "modesta vendola".

Momentos depois, outro viajante de poncho e chapéu largo a escorrerem água chegava à porta a pedir pousada, mas, avistando quem ali estava, saltou em terra e veio ao seu encontro. "Ó Senhor Conselheiro! O Senhor por aqui, com este tempo!” O chefe estendeu-lhe a mão, cordialmente, mas com mostras de certa hesitação no conhecimento do recém-chegado. Os atavios ensopados do viajante, o fato de o não ter visto havia muito ou um desses lapsos de memória visual a que todos são sujeitos, verdade foi que não reconheceu de pronto um seu dedicado correligionário de Morretes.

- "Então o senhor Conselheiro não conhece mais o F..., seu eleitor de sempre e capaz de dar a vida pelo senhor?” A impressão do chefe foi profundíssima, pela mágoa ocasionada ao fiel amigo. Desfez-se em explicações e desculpas e, depois de amistosa palestra, que se prolongou pela noite adiante, todo o ressentimento do incidente ficou dissipado; mas o chefe passou o resto da noite em claro e, nos seguintes dias de viagem, o filho lhe ouviu dizer, mais de uma vez: "Quanto me pesa a pena involuntária que dei àquele amigo fiel e dedicado!”. (Marcondes, 2009, p. 55)

O exemplo e seu alcance educativo, aqui, consistem na percepção que teve o filho quanto à conduta do pai no trato de um seu seguidor político, do Partido Liberal, que era minoria na cidade de Morretes, um dos redutos do Partido Conservador. A "lição" dada pelo exemplo é de que cada um desses correligionários, numa sociedade toda ela baseada na patronagem e no favor, deveria ser tratado com respeito da parte do político com maior evidência, uma vez que eram, na prática partidária, "amigos" fiéis e dedicados. Que eram fiéis e dedicados - no complicado jogo eleitoral do Império - é coisa a ser levada a sério, já que a fidelidade e dedicação à causa de um partido, não raras vezes, podiam colocar a vida do eleitor em risco, posto que a violência armada e as ameaças aos opositores eram frequentes na hora de comparecer às igrejas para dar o voto a alguém. Porém, que Jesuíno e o sr. F. fossem “amigos", já é algo mais questionável, sobretudo, pela dificuldade que aquele teve em identificar o seu correligionário, o que indica que seu convívio era mínimo e limitado ao tempo das eleições. Ainda assim, no relacionamento com o eleitorado, era de "amigo para amigo" que deviam ser tratados, pois, indubitavelmente, da adesão de cada um desses "amigos" é que políticos como Jesuíno Marcondes de Oliveira e Sá, embora detentores de poder econômico e político, conseguiam 
chegar, efetivamente, aos cargos públicos nos quais poderiam fazer uso prático desse poder, legislando quase sempre a favor da classe a que pertenciam, mas também, em prol daqueles que lhes eram fiéis. Essa foi a lição, dada pelo exemplo, que ficou gravada na memória do menino Moysés e, nesse sentido, tornou-se também elemento de sua educação, tanto quanto era constituidor do mundo dos Marcondes de Oliveira e Sá.

\section{DE PAI PARA FILHO: A INSTRUÇÃO \\ NA FAMÍlia dos Marcondes de Sá}

"É triste, duro e arriscado lançar um filho no mundo [...]. Deus que o faça bom e feliz, é tudo que peço, embora nos custe isso privações. Esta é a sorte dos pais; assim foi a dos nossos, e assim marchará sempre o mundo" - preocupações escritas quase como uma prece, nas cartas enviadas por Jesuíno Marcondes de Oliveira e Sá no ano de 1872 (Oliveira e Sá, 1872, apud Marcondes, 2009, p. 98). O filho lançado no mundo era Moysés, que estava com seus 13 anos, estudando no Seminário Episcopal de São Paulo. Perpetuando o exemplo dado por seu pai, que também o enviou desde muito pequeno para estudar em outras localidades, Jesuíno demonstra em suas cartas que usos eram esperados dessa instrução e o lugar a ela conferido.

Em se tratando de instrução, o zelo de Jesuíno, muitas vezes transformado em conselho paterno, voltou-se para as crianças de sua família - filhos(as), sobrinhos(as) e netos(as). Em uma de suas cartas, escrevia para a neta que se encontrava em Curitiba na época dos exames finais escolares, apresentando um cenário convidativo para o regresso da família para Palmeira - "os morangueiros estão com muitas frutas e flores. A parreira quer entrar pelas janelas e tem mais de cem cachos que vão crescendo para ti e teus irmãos" - e complementa que tudo isso está sem ser aproveitado, na falta das crianças, embora pondere: "quem cumprir bem com seus deveres há de vir à festa [...]. Tanta coisa sedutora para crianças. Mas na dependência dos deveres bem cumpridos" (Oliveira e Sá apud Marcondes, 2009, p. 66). Jesuíno nos permite identificar uma compreensão de que a infância era uma etapa distinta das outras, com demandas específicas, como o brincar. Todavia, antes do direito de se fartar nas atividades na casa dos avós vinha o dever: frequentar a escola, realizar os exames finais e neles ser bem-sucedido.

Com o filho, percebemos que Jesuíno também alçava a instrução como dever a ser cumprido, porém, havia uma pequena distinção nos apelos do pai. 
Acompanhemos sua correspondência percebendo indícios dessa diferença. Em 1863, tinha Moysés 4 anos e estava na casa de seus tios Joaquim Pacheco da Silva Rezende e Anna Marcondes Pacheco, quando Jesuíno escreveu que recebera a carta do filho e que sabia "que ele deseja ver antes doces e brinquedos do que a ferramenta das letras” (Oliveira e Sá, 1863, p. 1). Onze anos depois, provavelmente quando Moysés estava terminando os estudos no seminário paulista, identificamos o conselho paterno:

É preciso que estudes muito, para que os teus primeiros exames te deem boa reputação literária. Essa reputação, que se ganha nas aulas, é decisiva para toda a vida; e, para a conquista, é preciso trabalho, de que não podem prescindir nem os gênios; porque é lei divina que o homem nada consiga, senão com o suor do seu rosto. Não contes, meu filho, com cartas de proteção minhas, para teus exames. Não quero que sejas aprovado, mas sim que saibas. Por mais apertados que sejam esses exames, te sairás bem deles, se estudares bastante e fores bem preparado. Conta com teus estudos e tenha ânimo. (Oliveira e Sá apud Marcondes, 2009, p. 97)

Apesar de todo amor e zelo, Jesuíno deixou claro que não usaria de sua reputação ou poder como responsável para pedir comiseração dos mestres nos exames finais do filho. ${ }^{11}$ É presumível que a carta acima viesse em resposta a outra correspondência, enviada por Moysés, onde provavelmente contava ao pai da proximidade dos exames finais e, talvez, dos seus receios. Uma intimidade na relação entre pai e filho; uma ligação que permitia a ambos expor seus pensamentos de forma que, ao poder narrar ao pai sobre a proximidade dos exames finais, o filho ganhava orientação sobre como proceder - estudando bastante - para chegar ao seu objetivo que era a boa reputação literária. Uma primeira distinção quanto ao papel da instrução na vida do filho. Conhecer as palavras, compreender a literatura estudada, possibilitaria a ele a inserção em uma sociedade na qual ideias e conflitos se refletiam cada vez mais naquilo que é escrito; ter uma boa reputação literária seria, portanto, um diferencial nessa sociedade em fase de letramento.

Seis anos depois, a situação era diversa. Moysés, com 21 anos, havia passado pela Faculdade de Direito em São Paulo e cursava Medicina pela Universidade da Pensilvânia (EUA), quando seu pai pediu que observasse "a criação do gado, raças, queijo, manteiga, plantação do milho e trigo. Demora-te em Chicago, empório estupendo de produção americana. Deves aproveitar o tempo e observar coisas úteis ao nosso país, mesmo pelo lado político e administrativo" (Oliveira e Sá apud Marcondes, 2009, p. 58). Novamente podemos 
observar o pai aconselhando o filho, mas, além disso, percebemos que para Jesuíno a instrução, de forma institucionalizada, estava atrelada à formação do olhar aguçado para as possibilidades de futuros negócios e aprimoramento do jogo político.

De uma geração à outra os conselhos para com a instrução eram passados. Jesuíno acompanhava a instrução de seu filho desde o ensino elementar. O mesmo fizera seu pai com ele. Jesuíno, assim como o filho, saiu de casa para poder estudar. Estava com 7 anos quando foi enviado para Curitiba, a cem milhas de sua casa, para cursar o ensino elementar (Marcondes, 2009, p. 18). Identificamos semelhanças e diferenças quanto aos usos e sentidos dessa prática de enviar os filhos homens para estudar fora de Palmeira. Para José Caetano de Oliveira, a instrução comparecia como prática de distinção social. "Suas filhas haviam de saber ler e escrever, e, para tal fim, manteve as mais velhas em casa de seus parentes, em Sorocaba, o tempo preciso para a aquisição desses conhecimentos"; quanto aos meninos, "sua máxima aspiração era descobrir em alguns deles disposições para estudos superiores, no ideal de lhes proporcionar facilidades e meios para uma educação completa" (Marcondes, 2009, p. 18). Sendo homem de origem humilde, com pouco estudo, José Caetano de Oliveira via na instrução a possibilidade de solidificar as bases de sua família, garantindo não somente o domínio do trabalho com a terra, mas o domínio social.

Segundo nos relata Moysés Marcondes de Oliveira e Sá, em 1844 Jesuíno estava matriculado no curso de Direito em São Paulo ${ }^{12}$ e "os cuidados, conselhos e acertadas providências de seu pai acompanharam-no incessantemente" (Marcondes, 2009, p. 19). Três anos depois, retornando Jesuíno aos estudos na província de Pernambuco após um tempo em casa, seu pai escrevia: “já vos suponho em Olinda, e Deus permita sejais feliz na viagem e em vossos estudos, e que me deis gosto, se quereis conservar minha existência, como presumo". Sete meses depois, outro reforço: "só o que vos peço é que me deis gosto de vos ver concluir vossa carreira...” (Oliveira apud Marcondes, 2009, p. 20).

A carreira, a formatura como bacharel em Direito, tinha um apelo não somente vinculado à certeza de que o filho fosse capaz de prover seu sustento e de sua futura família; ela estava ligada a uma perspectiva que via nessa profissão um grau maior de poder. Sérgio Adorno (1988) pontua que "a Academia de Direito de São Paulo, assim como a de Olinda, tem suas raízes atadas à independência política" e que os sujeitos que lá se formavam eram aprendizes do poder (Adorno, 1988, p. 81). O referido autor afirma que a criação e a inauguração dos cursos jurídicos brasileiros tiveram como pretensão alcançar a 
autonomização política da sociedade por meio do individualismo político e do liberalismo econômico, e que podemos observar que durante o século XIX “o Estado brasileiro erigiu-se como um Estado de Magistrados", um Estado que buscava formar "uma elite intelectual aberta para a modernidade" (Adorno, 1988, p. 78, 95). Dessa forma, Jesuíno possuía a formação adequada e, consequentemente, uma oportunidade política e econômica diferenciada da que tinha José Caetano como fazendeiro dos Campos Gerais. Por isso a instrução aparece nas missivas enviadas pelo barão como um elemento de vitória, uma vez que, quando o filho obtivesse o grau maior, de doutor, poderia "[aparecer] na sociedade e [fazer] boa figura..." (Oliveira apud Marcondes, 2009, p. 21). No olhar retrospectivo, próprio do historiador, parece que Jesuíno e Moysés foram "vencedores", nos termos das aspirações familiares que, em diferentes gerações, recaíram sobre eles.

\section{CONSIDERAÇÕES FINAIS}

Ao esmiuçarmos o relato memorialístico "Pai e Patrono" (Marcondes, 2009), organizado por Moysés Marcondes de Oliveira e Sá, vislumbramos um pouco do mundo de sua família, percebendo a existência de dimensões (familiar, material, política e social) que se complementam e se fortalecem ao longo de duas gerações familiares. Podemos afirmar que, ao longo delas, o que unificava essas dimensões e dava sustentação a esse mundo, a partir da década de 1830, já não era apenas o trabalho (do qual José Caetano nunca se afastou), uma vez que a riqueza que dele provinha já estava consolidada em bens de raiz por volta de 1840. Tanto é que Jesuíno pôde abrir mão da vida no campo para receber a formação considerada mais adequada para uma carreira intelectual - o Direito -, completando-a, ainda, com uma viagem à Europa no início dos anos 1850. De igual maneira, seu filho Moysés, em fins de 1870, após bacharelar-se em Direito, foi estudar medicina nos Estados Unidos, buscando formação tão refinada quanto a do pai. Na documentação interrogada percebemos que a instrução diferenciada das novas gerações, somada a certa educação que transmitisse hábitos e comportamentos caros aos valores familiares, era a verdadeira argamassa a unir as diferentes dimensões do mundo dos Marcondes de Sá e, principalmente, a garantir a sua continuidade.

Para a educação e a instrução dos filhos, ambas as gerações valeram-se, nos momentos aqui flagrados, de práticas como o conselho paterno, tanto pessoal como epistolar, e o exemplo (fosse no sentido de exemplaridades a observar e imitar como do exemplo dado pelo pai ao filho). Em princípio essas 
práticas, segundo aponta uma pesquisa dedicada ao estudo da educação da criança pela família no Oitocentos (Anjos, 2015), eram as mesmas de que se valiam outros atores sociais do período, tanto no Brasil como em outros países. Mas na família dos Marcondes de Sá eram apropriadas com base nas representações que seus chefes tinham de um lugar social e de uma classe, visando, por um lado, inculcar nos filhos, pela educação, hábitos e condutas ligados a interesses e valores familiares, como a ampliação das riquezas e do poder político, sem descuidar do zelo pelo bem comum e da afirmação de sua identidade de elite campeira. Por outro lado, por meio da instrução - encarada como um dever a ser bem cumprido pelos filhos, desde a infância - alguns dos seus membros, geralmente os homens, como Jesuíno e Moysés, deveriam adquirir títulos e conhecimentos que lhes permitissem assumir postos na vida pública por meio dos quais sua posição como elite campeira poderia ser não só garantida efetivamente, como reconhecida pelos demais membros da sociedade campeira e paranaense, na qual o mundo dos Marcondes de Oliveira e Sá, desse modo, graças à educação e à instrução, estaria plenamente integrado.

\section{FONTES}

MARCONDES, Moysés. Pai e Patrono. Palmeira: Prefeitura Municipal, 2009.

OLIVEIRA, José Caetano de. Carta a Jesuíno Marcondes. BBPR. 22 mar. 1857, manuscrito.

OLIVEIRA E SÁ, Jesuíno Marcondes de. Carta a Joaquim Pacheco da Silva Rezende. BPPR. 11 mar. 1863, manuscrito.

\section{REFERÊNCIAS}

ADORNO, Sérgio. Os aprendizes do poder. Rio de Janeiro: Paz e Terra, 1988.

ALENCASTRO, Luiz Felipe de. Vida privada e ordem privada no Império. In: ALENCASTRO, Luiz Felipe de (ed.). História da vida privada no Brasil. 2. São Paulo: Companhia das Letras, 1997. p. 11-94.

ANJOS, Juarez José T. dos. Pais e filhos na Província do Paraná: uma história da educação da criança pela família. 2015. Tese (Doutorado em Educação) - Universidade Federal do Paraná (UFPR). Curitiba, 2015.

CERTEAU, Michel de. A escrita da História. Rio de Janeiro: Forense Universitária, 2002. 
CHARTIER, Roger. A história cultural: entre práticas e representações. Lisboa: Difel, 2002.

GUTIÉRREZ, Horácio. Demografia escrava numa economia não-exportadora: Paraná, 1800-1830. Estudos Econômicos, v. 17, n. 2, p. 310-311, 1987.

HAIDAR, Maria de Lourdes M. O ensino secundário no Brasil Império. São Paulo: Edusp, 2008.

MELO, Mário Sérgio de; MORO, Rosemeri S.; GUIMARÃES, Gilson B. Os Campos Gerais do Paraná. In: MELO, Mário Sérgio de; MORO, Rosemeri S.; GUIMARÃES, Gilson B. (org.). Patrimônio natural dos Campos Gerais do Paraná. Ponta Grossa: Uepg, 2007. p. 17-22.

OLIVEIRA, Mariani B. Cruz de. Terra, trabalho e escravo: fortunas escravistas nos Campos Gerais Paranaenses (1826-1850). In: ENCONTRO ESTADUAL DE HISTÓRIA - ANPUH/RS, 12., 11 a 14 ago. 2014, São Leopoldo: Universidade do Vale do Rio dos Sinos (Unisinos). Anais... [eletrônicos]. São Leopoldo: Anpuh/RS, 2014. PERROT, Michelle. Introdução. In: PERROT, Michelle (org.). História da Vida Privada. 4. São Paulo: Companhia das Letras, 2009. p. 7-19.

POLLAK, Michael. Memória e identidade social. Estudos Históricos, Rio de Janeiro: CPDOC/FGV, v. 5, n. 10, p. 200-212, 1992.

POMIAN, Krzysztof. Memória. In: ENCICLOPÉDIA EINAUDI. Lisboa: Imprensa Nacional - Casa da Moeda, 2000. v. 42, p. 507-516.

SANTOS, Zeloí Maria dos. Visconde de Guarapuava: um personagem na História do Paraná. 2005. Tese (Doutorado em História) - Universidade Federal do Paraná (UFPR). Curitiba, 2005.

THOMPSON, Edward P. A formação da classe operária inglesa. v. 1. Rio de Janeiro: Paz e Terra, 2004.

\section{NOTAS}

${ }^{1} \mathrm{O}$ autor também é professor no programa de pós-graduação em Educação, Modalidade Profissional (ProfHistória), na Universidade de Brasília (UnB).

${ }^{2}$ A autora é pesquisadora do Núcleo de Estudos e Pesquisas em Infância e Educação Infantil (NEPIE) da Universidade Federal do Paraná (UFPR).

${ }^{3}$ Em uma interpretação da sociedade patriarcal durante o período aqui investigado, provavelmente esperava-se na ocasião o nascimento de um menino, mas a esposa de Jesuíno deu à luz uma filha. O segundo filho de Jesuíno foi também uma menina, falecida na infância. Somente na terceira gravidez é que veio o tão aguardado filho homem que, seguindo os ditames sociais, seria aquele que manteria a autoridade institucional delegada aos homens, que seriam os herdeiros de suas famílias e estavam acima da mulher em todas as organiza- 
ções sociais, tais como: política, legislação, produção, comércio, legislação etc. Com o nascimento do filho varão se garantiria a manutenção da sociedade patriarcal vivenciada.

${ }^{4}$ Elite campeira é a designação dada aos fazendeiros de gado e tropeiros da região dos Campos Gerais paranaense, que se distinguiram dos demais envolvidos nessas atividades por terem, com ela, por meio de alianças e relações de patronagem (além de boa dose de sorte, num empreendimento deveras arriscado), alcançado riqueza e posição social, tornando-se detentores de poder econômico e político no Paraná, atuando em diversos setores da administração pública local.

${ }^{5}$ Por classe, definimos, com E. P. Thompson, aquele fenômeno histórico que "acontece quando alguns homens, como resultado de experiências comuns (herdadas ou partilhadas), sentem e articulam a identidade de seus interesses entre si, e contra outros homens, cujos interesses diferem (e geralmente se opõem) aos seus" (THOMPSON, 2004, p. 10). Ao nos aproximarmos de Thompson, um historiador social, intentamos aqui ultrapassar aparentes fronteiras teóricas (história social/história cultural) para chegar à escrita do que Roger Chartier denomina "história cultural do social" (CHARTIER, 2002, p. 19).

${ }^{6}$ Em alguns momentos, contudo, recorreremos também a algumas correspondências dessa família, existentes no acervo da Biblioteca Pública do Paraná. À Josefina, chefe da Seção Paranaense, agradecemos a permissão para consulta do material.

${ }^{7}$ Para governo do leitor, nas referências no corpo do texto, usamos "Oliveira" para nos referirmos às correspondências de José Caetano de Oliveira, barão de Tibagy, tanto originais como publicadas em "Pai e Patrono"; "Oliveira e Sá" para nos remetermos às correspondências de seu filho, Jesuíno Marcondes de Oliveira e Sá, publicadas em "Pai e Patrono"; e "Marcondes" para nos referirmos a Moysés Marcondes e à sua obra memorialística propriamente dita. Respeitamos, assim, o modo como esses personagens assinavam suas missivas e obras. O recurso ao apud, quando necessário, indicará, com precisão, a localização de cada um desses testemunhos na edição de 2009 da obra "Pai e Patrono", publicada pela prefeitura municipal de Palmeira (PR) e que por nós foi utilizada. Para não sobrecarregar as referências finais, porém, optamos por referenciar somente a obra de Marcondes (2009) e, quando utilizadas, apenas as correspondências manuscritas de Oliveira e Sá e Oliveira, existentes na Biblioteca Pública do Paraná.

${ }^{8}$ Em síntese, essa prática de deixar outro responsável ou intermediário na fazenda, administrando terras, casa e empregados, é conceituada como absenteísmo. Em estudo demográfico sobre as fazendas de gado do Paraná, Horácio Gutiérrez (1987) aponta que o absenteísmo foi maior no século XVIII, sendo mínimo no século XIX: “Três quartos dos fazendeiros residiam em suas próprias fazendas e outros vinte por cento em uma das várias possuídas" (GUTIÉRREZ, 1987, p. 4). No entanto, apesar de Jesuíno não circular entre suas fazendas, saía em viagem para tratar de outros assuntos, como, por exemplo, os que tramitavam no campo da política.

${ }^{9}$ A título de exemplo, uma evidência do aburguesamento vivenciado no Rio de Janeiro do século XIX era o crescente interesse das famílias endinheiradas pela aquisição de pianos, como sinal de status e civilização. "Comprando um piano, as famílias introduziam um móvel aristocrático no meio de um mobiliário doméstico incaracterístico e inauguravam - no sobrado urbano ou nas sedes das fazendas - o salão: um espaço privado de sociabilidade que 
tornará visível, para observadores selecionados, a representação da vida familiar" (ALENCASTRO, 1997, p. 47). Nessa direção, Moysés Marcondes, falando da personalidade do pai, afirma que "aos gostos da simplicidade campestre associava ele as necessidades do homem educado: certo número de bons livros, revistas, jornais e até piano, nada disso faltou às instalações rurais, em que ele interveio" (MARCONDES, 2009, p. 105). Sobre a chegada do piano, Moysés Marcondes transcreve a seguinte carta paterna, sem data: "Hoje chegou o piano. Foi uma grande festa, na fazenda. Todo o pessoal compareceu ao desencaixe, que foi longo. Quando a frente ficou desembaraçada das caixas de madeira e zinco, isto no porão do terreiro, tua irmã não pode conter-se, no desejo de conhecer as vozes do instrumento e, ali mesmo, rodeada pela família, carpinteiros e camaradas, o estreou com a Ave Maria de Gounod" (MARCONDES, 2009, p. 105). Os Marcondes de Sá, como se vê, também trataram de adquirir o seu piano, como forma de se diferenciarem das famílias das classes médias e pobres da região, ainda que deixando-nos exposta um pouco da rusticidade e simplicidade do contexto rural em que o núcleo familiar se originou.

${ }^{10}$ Tanto os conselhos paternos quanto o ensino através do exemplo foram práticas largamente utilizadas pelas famílias na educação de seus filhos no século XIX, embora por elas apropriadas de formas diferenciadas. Trata-se, todavia, de temática ainda pouco explorada na historiografia da educação. Ao leitor interessado em verificar o lugar dessas práticas na sociedade e segmento social aqui estudado, mas também em outros grupos sociais, indica-se a leitura de Anjos (2015), particularmente o livro 3, capítulos 1, 2 e 3, onde são investigadas diversas famílias e contextos.

${ }^{11}$ A prática do apadrinhamento em exames escolares no nível do ensino secundário - aqui apresentada com o detalhe de eventuais cartas de que alguns pais se valiam para obter a aprovação dos filhos e, possivelmente, no caso de Moysés Marcondes, referindo-se aos exames parcelares de acesso ao ensino superior -, apesar de denunciada e formalmente rechaçada pelas autoridades do ensino, era bastante comum no Oitocentos. Em estudo hoje clássico, Maria de Lourdes Haidar já observava: "A desorganização das aulas menores e os desmandos dos professores de tais cursos atuavam como péssimos modelos; as irregularidades de toda ordem registradas nos exames de preparatórios desencorajavam estudos sérios e perseverantes; uma boa carta de empenho poderia abrir portas muitas vezes fechadas ao mérito e ao saber" (HAIDAR, 2008, p. 49).

${ }^{12}$ Terminou o referido curso em Olinda, pois teve uma desavença durante o exame do terceiro ano do curso em São Paulo. Formou-se em 23 de outubro de 1849. O motivo da desavença, descrito no livro, foi: "procurou-se justificar o caso pela má disposição de um lente, para quem o aluno não se mostrara tão submisso quanto as praxes acarretadas de Coimbra o exigiam. O pai não deixou de aconselhar ao filho, nessa ocasião, toda a deferência devida aos mestres, mas percebe-se claramente de sua correspondência ter sido ele o primeiro a sentir que o filho fora vítima inocente do cego partidarismo, já então em plena florescência no país" (MARCONDES, 2009, p.19 e 24). 